\title{
ДИФФЕРЕНЦИАЦИЯ ЗАДАНИЙ ПРИ ОБУЧЕНИИ ИНОСТРАННЫМ ЯЗЫКАМ ЛЮДЕЙ С ОСОБЫМИ ОБРАЗОВАТЕЛЬНЫМИ ПОТРЕБНОСТЯМИ (НА ПРИМЕРЕ АНГЛИЙСКОГО ЯЗЫКА)
}

\author{
Ю. А. Монашева, О. Н. Мальцева \\ Московский гуманитарный университет
}

\begin{abstract}
Аннотация: В статье рассматривается вопрос интегрированного обучения иностранным языкам людей с особыми образовательными потребностями и метод дифференциации заданий при подготовке преподавателей к занятиям иностранным языком в высших учебных заведениях.
\end{abstract}

Ключевые слова: инклюзивное образование; социальная модель инвалидности; особые образовательные потребности; дифференциация; иностранный язык

\section{DIFFERENTIATION OF TASKS IN TEACHING FOREIGN LANGUAGES TO PEOPLE WITH SPECIAL EDUCATIONAL NEEDS (EXEMPLIFIED BY THE ENGLISH LANGUAGE)}

\author{
Yu. A. Monasheva, O. N. Maltseva \\ Moscow University for the Humanities
}

Abstract: The article covers the issue of integrated teaching of foreign languages to people with special educational needs and the method of differentiating tasks in teachers' preparation for foreign language classes in higher educational institutions.

Keywords: inclusive education; social model of disability; special educational needs; differentiation; foreign language

В настоящее время в России, как и во многих других государствах, проводится инклюзивная образовательная политика, в связи с чем количество обучающихся с особыми образовательными потребностями постоянно растет. Инклюзивное образование подразумевает совместное обучение всех членов общества на всех ступенях образования, что указано в Федеральном законе Российской Федерации «Об образовании в Российской Федерации»: «инклюзивное образование - обеспечение равного доступа к образованию для всех обучающихся с учетом разнообразия особых образовательных потребностей и индивидуальных возможностей» ${ }^{1}$.

\footnotetext{
${ }^{1}$ Федеральный закон «Об образовании в Российской Федерации» от 29.12.2012 №273Ф3: [Электронный ресурс] // Консультант. URL: http://www.consultant.ru/document/ cons_doc_LAW_140174/ (дата обращения: 05.11.2019).
} 
Научные труды Московского гуманитарного университета 2019 № 6

В настоящее время существуют две основные теоретические модели отношения к людям с особыми образовательными потребностями: медицинская модель и социальная модель понимания инвалидности.

Согласно медицинской модели, обучающийся с особыми образовательными потребностями имеет патологию, которая не дает ему возможности полноценно функционировать в обществе. В рамках этой модели создана отдельная система обучения и учебные заведения, где применяется методика, предполагающая лечение, обучение и трудотерапию в изоляции от общества.

Социальная модель понимания инвалидности была создана в противовес медицинской модели с целью продемонстрировать, что особые возможности здоровья могут быть нормальным аспектом жизни индивида и общества и уничтожить социальную дискриминацию людей с особыми возможностями здоровья. В соответствии с этой моделью «человек с инвалидностью должен быть равноправным субъектом общественных отношений, которому общество должно предоставить равные права, равные возможности, равную ответственность и свободный выбор с учетом его особых потребностей» (Зак, 2008: 24). Таким образом, не отрицая физиологических особенностей человека, такая модель предлагает реализацию гражданских прав людей с особыми образовательными потребностями посредством совместного интегрированного обучения на всех этапах образовательного процесса по всем предусмотренным образовательной программой дисциплинам.

Говоря о социальной модели понимания инвалидности, особое внимание следует уделить обучению иностранным языкам. Процесс изучения языка помогает обучающимся с особыми образовательными потребностями социализироваться, ликвидируя трудности общения с остальными участниками группы, так как именно на занятиях иностранным языком все обучающиеся группы, вне зависимости от их возможностей и потребностей, оказываются в одинаковой коммуникативной среде. Это позволяет реализовать главный принцип инклюзивного образования, заключающийся в социализации людей с особыми образовательными потребностями.

В отличие от педагогов школ, преподаватели высших учебных заведений не имеют возможности постоянно контактировать с родственниками и опекунами обучающихся с особыми образовательными потребностями и совместно с ними создавать благоприятные условия для обучения. В связи с этим преподаватели вузов должны быть осведомлены о том, кто из студентов их группы имеет особые образовательные потребности, а также о методах работы в инклюзивных группах, чтобы создать оптимальные условия на занятии для всех участников образовательного процесса. При обуче- 
нии иностранному языку студентов с особыми образовательными потребностями в рамках групповых занятий основными задачами преподавателя, наряду с формированием у всех обучающихся знаний, умений и навыков, предусмотренных образовательной программой, являются вовлечение в образовательный процесс всех обучающихся и создание мотивации к обучению.

Одним из простых и доступных для всех преподавателей способов решения поставленных задач является применение метода дифференциации заданий с учетом возможностей и способностей каждого участника группы.

Дифференциация предполагает адаптацию преподавателем некоторой части заданий и материалов в соответствии с потребностями отдельных студентов, чтобы обеспечить вовлечение всех обучающихся в работу на занятии. Все они должны достичь одной и той же основной цели занятия, но средства и способы достижения этой цели могут отличаться. При дифференциации работы на занятии каждый студент получает возможность продемонстрировать свои достижения, почувствовать свой прогресс и, следовательно, повысить свою самооценку и иметь мотивацию продолжать обучение.

Дифференциацию следует проводить при подготовке заданий и материалов для работы со всеми видами речевой деятельности на занятии: чтением, письмом, аудированием и говорением.

При работе с иноязычными текстами для контроля понимания содержания прочитанного материала возможна дифференциация типовых заданий. При составлении заданий с несколькими вариантами ответов следует варьировать количество возможных вариантов ответов на один и тот же вопрос. В заданиях на поиск ложных и истинных утверждений из списка предложенных преподаватель может ввести или исключить опцию исправления ложных утверждений.

Дифференциация в процессе работы с письменной речью является одной из наименее сложных задач для преподавателя. Дифференцировать можно требования к объему письменной работы и сложность темы. Для упрощения работы над сочинением или эссе можно предложить обучающимся примеры подобных текстов, а также провести «мозговой штурм» идей со всей группой. Одним из видов дифференцированных письменных заданий является задание коллективного сочинения.

Проводя работу по аудированию, преподаватель, как правило, не имеет возможности упростить или усложнить аудиоматериалы, но у него есть возможность варьировать количество повторений прослушивания и уровень сложности заданий. Для лучшего понимания услышанного студентам можно предложить текстовый вариант аудиоматериалов. 
Особое внимание при обучении иностранному языку уделяют говорению, как самому сложному виду речевой деятельности. Существуют различные приемы для дифференциации говорения: использование визуальных и аудиоматериалов, интерактивных заданий с разным уровнем сложности, групповые полилогические задания, в процессе выполнения которых студенты с разным уровнем подготовки способны помогать и корректировать друг друга. При обучении студентов с особыми образовательными потребностями не рекомендуется сразу исправлять ошибки в устной речи обучающихся, так как это может демотивировать их. Следует записывать ошибки и прорабатывать их после выполнения задания, побуждая обучающихся самостоятельно их исправлять.

Исходя из вышесказанного, можно выделить три способа дифференциации учебных материалов при обучении иностранному языку:

1. дифференциация содержания;

2. дифференциация заданий;

3. дифференциация ответов.

Дифференциация содержания заключается в упрощении или усложнении содержания заданий. Например, при работе с текстом для чтения, студентам предлагаются тексты разного уровня сложности, содержащие при этом одинаковую информацию. Это позволяет каждому работать в своем темпе и на своем уровне, выполняя при этом одну и ту же задачу.

Таблица 1. Дифференциация содержания текста

Text A

Read and answer:

Frank goes to a big university in the city. He goes by bus. He leaves home at 8 o'clock. He has four classes. He goes back home at 3 o'clock.

How does Frank get to university? What time does he leave home? How many classes does he have? What time does he go back home?

\section{Text B}

Read the text and answer the questions:

Frank is 18 years old and goes to a large university in the city. He leaves home early, at 8 o'clock, and catches the bus to get to the university. He has four classes every day, but he usually gets bored by the end of the second class and he finds it very difficult to wait till the end of the following two classes. Finally he goes back home at 3 o'clock.

How does Frank get to university?

What time does he leave home?

How many classes does he have?

What time does he go back home?

Как видно из примера в таблице 1 , в задании «Теxt A» используются только короткие предложения, а информация изложена явно, кратко, без 
дополнительных фактов. В задании «Техt В», в свою очередь, использованы сложные распространенные предложения, а требуемую информацию нужно искать в тексте.

Дифференциация заданий происходит по уровню сложности и разнообразию, что достигается конкретизацией заданий, сокращением или увеличением объема упражнений и подготовительными инструкциями.

Таблица 2. Дифференциация задания по уровню сложности

\begin{tabular}{|c|c|}
\hline $\begin{array}{l}\text { Task A } \\
\text { Write a short text about yourself. Intro- } \\
\text { duce yourself and write about your origin, } \\
\text { age, interests, favourite food and favourite } \\
\text { sport. }\end{array}$ & Task B \\
\hline \multirow{8}{*}{$\begin{array}{l}\text { Write a short text about yourself. Intro- } \\
\text { duce yourself and write about your origin, } \\
\text { age, interests, favourite food and favourite } \\
\text { sport. }\end{array}$} & Complete these sentences about yourself: \\
\hline & My name is \\
\hline & I'm from \\
\hline & 1110 \\
\hline & I'm ___ years old. \\
\hline & I like ___ and ___ \\
\hline & My favourite food is \\
\hline & My favourite sport is \\
\hline
\end{tabular}

В таблице 2 представлены задания разного уровня сложности. Задание «Task A» предполагает самостоятельное составление предложений по заданной теме, для чего нужно понимать поставленный вопрос и знать принципы построения и структуру английских фраз. В задании «Task B» требуется только дополнить фразы, при этом акцент делается на отдельные лексические единицы, а не на построение всей фразы.

Таблица 3. Дифференциация способов ответа на задание

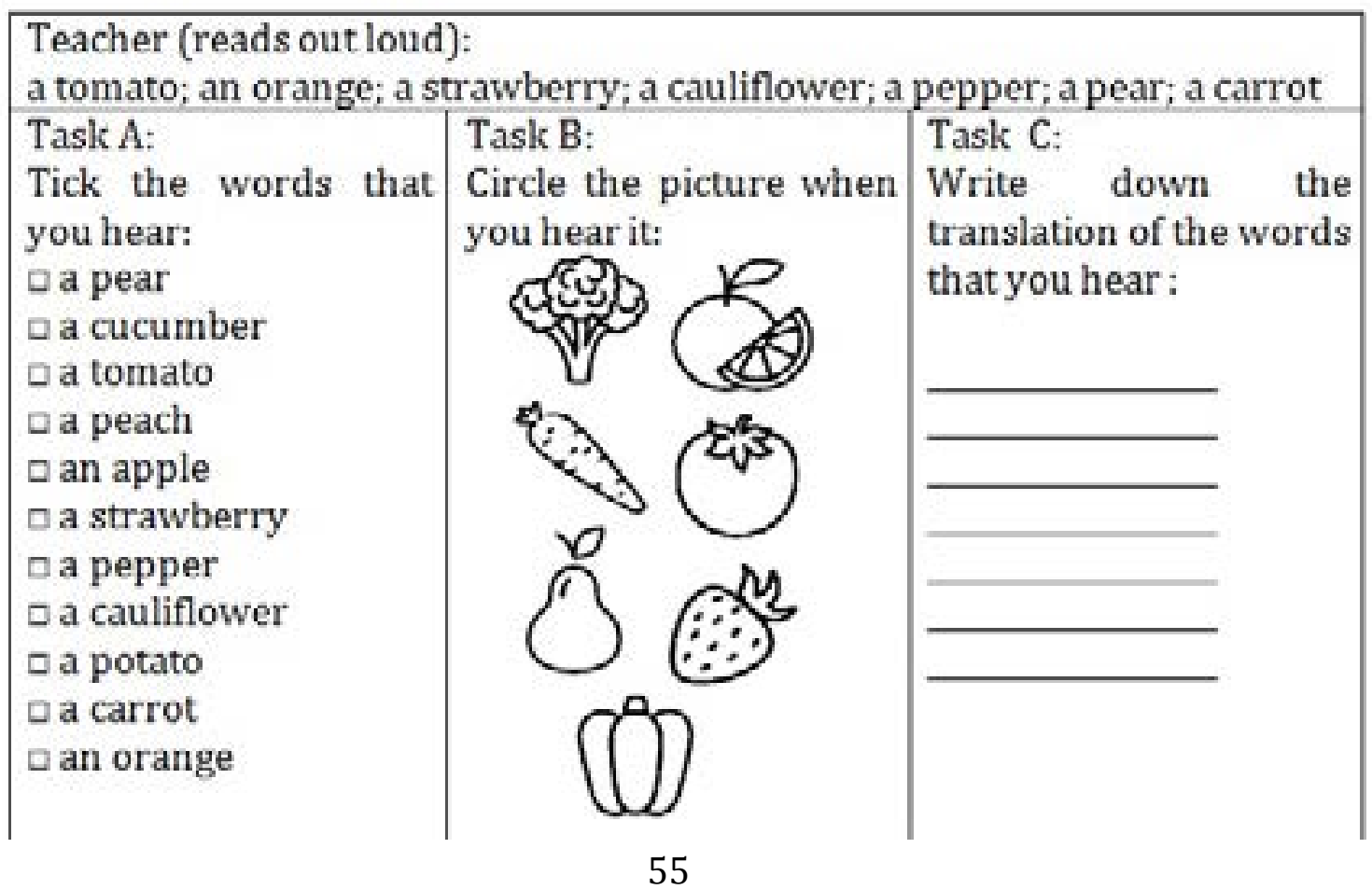


При дифференциации ответов преподаватель предлагает разные способы дать ответ и по-разному отреагировать на вопрос/задание обучающимся с разными образовательными потребностями.

Задания в таблице 3 демонстрируют пример дифференциации ответов: каждый тип упражнения в разделах «Task A», «Task B» и «Task C» подразумевает реакцию на задание преподавателя различными способами, в зависимости от особенностей мышления и восприятия обучающегося. Таким образом, преподаватель обеспечивает комфортные условия обучения и результативность работы студентов на занятии.

В заключение следует отметить, что метод дифференциации при подготовке к занятиям в инклюзивных группах применим и эффективен при обучении любому иностранному языку и может быть рекомендован для работы с группами разных уровней владения иностранным языком.

\section{СПИСОК ЛИТЕРАТУРЫ}

Зак, Г. Г. (2008) Историко-генетический анализ инвалидности как социальной проблемы // Специальное образование. № 2 (10). С. 22-24

Дата поступления: 06.11.2019 г.

Монашева Юлия Андреевна - специалист Лингвистического центра, доцент кафедры иностранных языков Московского гуманитарного университета. Адрес: 111395, Россия, Москва, ул. Юности, д. 5. Тел.: + 7 (499) 374-7592. Эл. адрес: yumonasheva@mosgu.ru

Мальцева Ольга Николаевна - доцент кафедры иностранных языков Московского гуманитарного университета. Адрес: 111395, Россия, Москва, ул. Юности, д. 5 Тел.: +7 (499) 374-75-92. Эл. адрес: bettiboo@yandex.ru

Monasheva Yuliya Andreevna, Manager, Language Center; Associate Professor, Department of Foreign Languages, Moscow University for the Humanities. Postal address: 5, Yunosti St., Moscow, Russian Federation, 111395. Tel.: +7 (499) 374-75-92. E-mail: yumonasheva@mosgu.ru

Maltseva Olga Nikolayevna, Associate Professor, Department of Foreign Languages, Moscow University for the Humanities. Postal address: 5, Yunosti St., Moscow, Russian Federation, 111395. Tel.: +7 (499) 374-75-92. E-mail: bettiboo@ yandex.ru

\section{Для цитирования:}

Монашева Ю. А., Мальцева О. Н. Дифференциация заданий при обучении иностранным языкам людей с особыми образовательными потребностями (на примере английского языка) [Электронный ресурс] // Научные труды Московского гуманитарного университета. 2019. № 6. URL: http://journals.mosgu.ru/trudy/article/view/1098 (дата обращения: дд.мм.гг.). DOI: 10.17805/trudy.2019.6.7 